\title{
AHP-Based Approach for Lighting System Selection in an Underground Parking
}

\author{
Pablo Pérez-Gosende, MSc. ${ }^{1-2}$ \\ ${ }^{1}$ Universidad Politécnica Salesiana, Ecuador, pperezg@ups.edu.ec \\ ${ }^{2}$ Universitat Politècnica de València, Spain, pabpego3@doctor.upv.es
}

\begin{abstract}
This research aims to identify the most suitable lighting system for an underground parking in an academic building according to international standards. Nine lighting systems scenarios were evaluated and the most suitable was selected considering experts criteria through an Analytical Hierarchical Process (AHP). The decision criteria considered were: total power, average lifespan, life-cycle cost, illuminance, uniformity, glare, energy efficiency, color rendering and energy saving, some of which were simulated through DIALux software. Among these criteria, the uniformity of the illuminance was the most influential criterion in the final decision according to experts' judgement. Contrariwise, glare and color rendering were the least important criteria. As a result, a LED technology lighting system with an expected annual energy saving of 35\% turned out the most suitable for the indoor facility under study.
\end{abstract} parking.

Keywords- AHP, DIALux, lighting system, underground

\section{INTRODUCTION}

It is known that approximately $21 \%$ of all electricity produced in the world is consumed in lighting [1], and even that it constitutes an important part of the total electricity consumption of a country [2]. In particular, in industrialized countries it has been reported that lighting accounts for $20 \%$ of total energy consumption [3].

The optimization of the electrical energy consumption of indoor lighting systems is a matter of great interest for the scientific community [4]. Some studies show that the electrical energy consumed in the lighting systems represent $50 \%$ of the total energy consumption in office buildings, between $20 \%$ and $30 \%$ in hospitals, $15 \%$ in manufacturing factories and from 10 to $15 \%$ in schools [4], [5].

Thus, with the aim of reducing energy consumption in buildings, one of the feasible strategies is the design and implementation of more efficient interior lighting systems [6]. However, in addition to energy efficiency, the design of an interior lighting system should consider the visual performance and comfort of the users [1]. It is then sought that lighting provides a pleasant and stimulating environment that allows users to perform their activities without excessive visual effort, avoiding fatigue, headaches and the prevalence of vision disorders caused by inadequate lighting [7].

In Ecuador, the bylaw that regulates illumination is not very demanding, or at least not very precise in terms of the levels of lighting suitable for each activity. On the other hand, public or private institutions are not required to carry out light

Digital Object Identifier (DOI):

http://dx.doi.org/10.18687/LACCEI2019.1.1.252

ISBN: 978-0-9993443-6-1 ISSN: 2414-6390 audits to detect deficiencies in their lighting systems. Therefore, it is extremely important to give concrete answers to the reduction of energy consumption in buildings through the search for more efficient lighting alternatives without neglecting compliance with current regulations regarding health and safety.

Despite the wide coverage of academic studies regarding indoor lighting, only a few studies have particularized in the analysis of underground parkings [8]. In this context, this paper proposes a strategy of energy saving for an underground parking that involves the replacement of a traditional lighting system based on fluorescent technology for a more energetically efficient and safe one to the users.

This research is part of a larger project named "Energetically sustainable campus model" developed by the Interdisciplinary Research Group in Applied Mathematics (GIIMA) of Universidad Politécnica Salesiana, Ecuador, in conjunction with the Interdisciplinary Modeling Group (InterTech) of Universitat Politècnica de València in Spain. The results of the project will allow optimizing the energy consumption for lighting, air conditioning and computers use at the Ecuadorian academic institution in the medium term.

\section{METHODS}

The research was quantitative with a descriptive approach. The underground parking object of study is located in an academic building of one of the most important universities in the city of Guayaquil, Ecuador.

The norm that regulates indoor and outdoor lighting levels in Ecuador is the Decree 2393 Regulation of Safety and Health of Workers and Improvement of the Work Environment [9], however, this regulation in force since 1986 does not establish specific values for underground parking due to its generality.

Given the lack of specificity of the Ecuadorian regulations, in this research it was taken as reference the European standard on indoor lighting EN 12464.1, which includes minimum illuminance values for underground parking in academic buildings [7]. For these areas, the above mentioned standard establishes the values of maintained illuminance (Em), glare (measured in Unified Glare Rating, UGR) and colour rendering index (CRI) that are presented in Table 1 .

The measurements of the illuminance levels were made in February 2019 by means of two AMPROBE lux meters model LM100, with an accuracy of $\pm 5 \%+5$ digits. The dimensions of the facilities were obtained by means of a Capital laser 
distance meter model CP-3007, with accuracy of $\pm 0.5 \%$ and resolution of $0.01 \mathrm{~m}$.

TABLE I

LIGHTING REQUIREMENTS FOR UNDERGROUND PARKINGS IN EN 12464.1 STANDARD

\begin{tabular}{|l|c|c|c|}
\hline Areas & Em & UGR & CRI \\
\hline $\begin{array}{l}\text { Access or exit ramps } \\
\text { (daytime) }\end{array}$ & $3001 \mathrm{x}$ & $<25$ & $>20$ \\
\hline $\begin{array}{l}\text { Access or exit ramps (at } \\
\text { night) }\end{array}$ & $75 \mathrm{~lx}$ & $<25$ & $>20$ \\
\hline Circulation lanes & $75 \mathrm{~lx}$ & $<25$ & $>20$ \\
\hline Parking areas & $75 \mathrm{~lx}$ & - & $>20$ \\
\hline
\end{tabular}

Source: EN 12464.1 [7]

By mean of the DIALux 4.12 software, the facility was modelled and nine scenarios were simulated with different types of luminaires. In every scenario there were considered the total power, the maintained illuminance, the illuminance uniformity, the glare and the energy efficiency (expressed in $\mathrm{lm} / \mathrm{W}$ ). Also, it was considered the behaviour of other variables that depend on the selected luminaire type, such as the lifespan and the color rendering index. Similarly, in each case the lighting system life-cycle cost was measured, as well as the savings that its implementation would represent with respect to the system currently implemented.

The relevant cost items for the calculation of the lighting system life-cycle cost (LCC) are considered in (1). There, AC stands for the luminaires acquisition cost, $\mathrm{FC}$ the light fitting cost and $\mathrm{EC}_{\mathrm{L}}$ the energy cost to run the system for its entire lifetime. Equation (2) was used to obtain $\mathrm{EC}_{\mathrm{L}}$. There, $\mathrm{n}$ represents the quantity of lamps required, $\mathrm{P}$ the total power consumed by the luminaire, $\mathrm{L}$ the estimated lifespan (measured in hours) and $\mathrm{T}$ the electric rate $(\$ / \mathrm{kWh})$. In addition, the annual economic benefit represented by the energy saving through the use of the lighting system under analysis compared to the current implemented system was denoted ES and it is calculated as in (3). This last magnitude depends on CEt and $\mathrm{CEc}$, which refer respectively to the annual energy consumption of the lighting system on trial and the one already implemented.

$$
\begin{gathered}
L C C=A C+F C+E C_{L} \\
E C_{L}=10^{-3} n P L T \\
E S=100(1-C E t / C E C)
\end{gathered}
$$

Then, through the Analytical Hierarchical Process (AHP) [10], with the help of a group of twelve experts, the most feasible scenario was determined taking as reference the technical requirements established in the European standard EN 12464.1 among other relevant technical and economic criteria that were above mentioned.

To set the decision criteria paired comparisons matrix, conventional Saaty's scale was used, meaning: 9=Absolutely more important, $7=$ Much more important, 5=More important, $3=$ Moderately more important, $1=$ Equal importance, $1 / 3=$ Moderately less important, $1 / 5=$ Less important, $1 / 7=$ Much less important and 1/9=Absolutely less important [10].

Through a survey, the experts assigned values of importance for each pair of criteria. The consensus among the experts' assessments was measured through the Friedman test and the Kendall concordance test. Then, the modal values of importance established by the experts were considered in the determination of the eigenvector of the paired comparisons matrix of the AHP method.

\section{RESULTS}

The underground parking under study is located in the basement of an academic building of one of the most important institutions of higher education in Ecuador. Its dimensions are: $59.10 \mathrm{~m}$ long, $17.52 \mathrm{~m}$ wide and $3.02 \mathrm{~m}$ high. The parking has a capacity for 30 cars arranged in two parking areas separated by a circulation lane $6 \mathrm{~m}$ wide. The entrance and exit of the vehicles takes place through a ramp that leads to the main street, as shown in Fig. 1.

The parking lot offers its services from Monday to Saturday from 07:00 a.m. to 11:00 p.m. and the lights are turned on every day at 6:00 p.m. According to the above, in this study it has been considered that the lighting system remains on 5 hours a day, 288 days a year.

The current lighting system under operation comprise 24 Feilosylvania 0056138 Sylproof Superia luminaires suspended $0.5 \mathrm{~m}$ from the ceiling. Each luminaire contains two T8 tubular fluorescent lamps, each one with a nominal power of $18 \mathrm{~W}$. The illuminance measurements were taken at night, between 7:00 p.m. and 10:00 p.m. at ground level in 15 different points. Then, the simulation of the system through DIALux 4.12 considering five calculation surfaces as shown in Fig. 2 and a

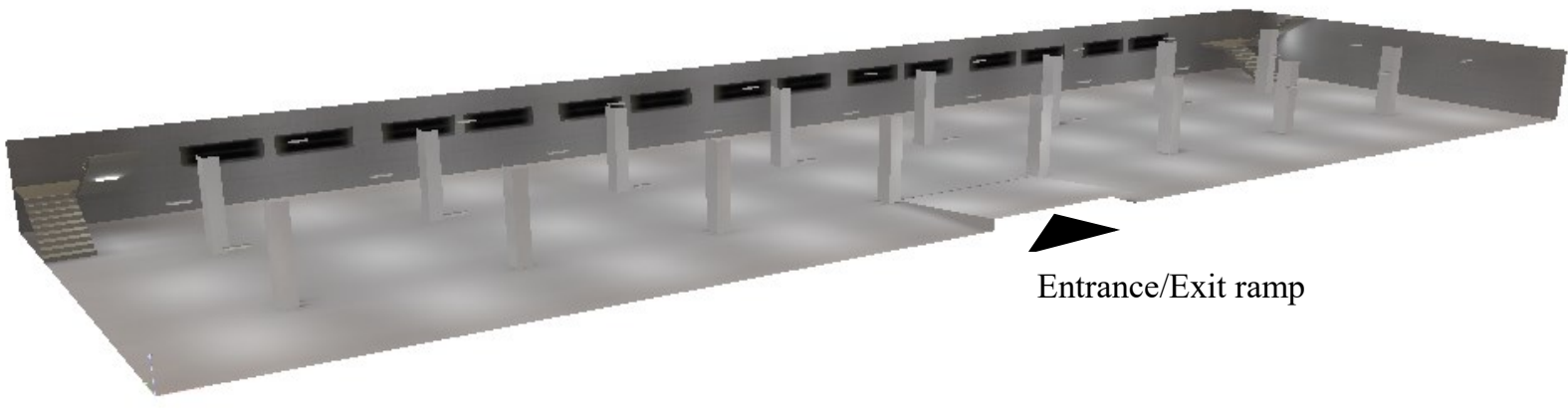

Fig. 1 Isometric view of the underground parking modelled in DIALux 4.12.

$17^{\text {th }}$ LACCEI International Multi-Conference for Engineering, Education, and Technology: "Industry, Innovation, And Infrastructure for Sustainable Cities and Communities", 24-26 July 2019, Jamaica. 


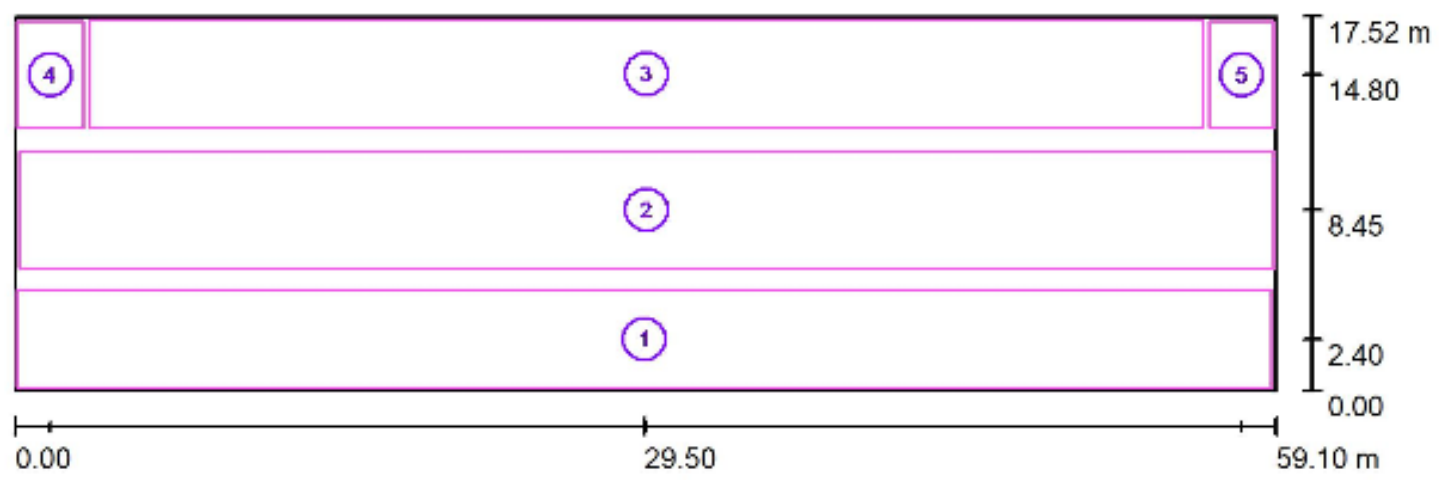

Fig. 2 Spatial arrangement of the five calculation surfaces considered for the simulation in DIALux: (1) and (3) parking lots, (2) circulation lane, (4) and (5) access stairs.

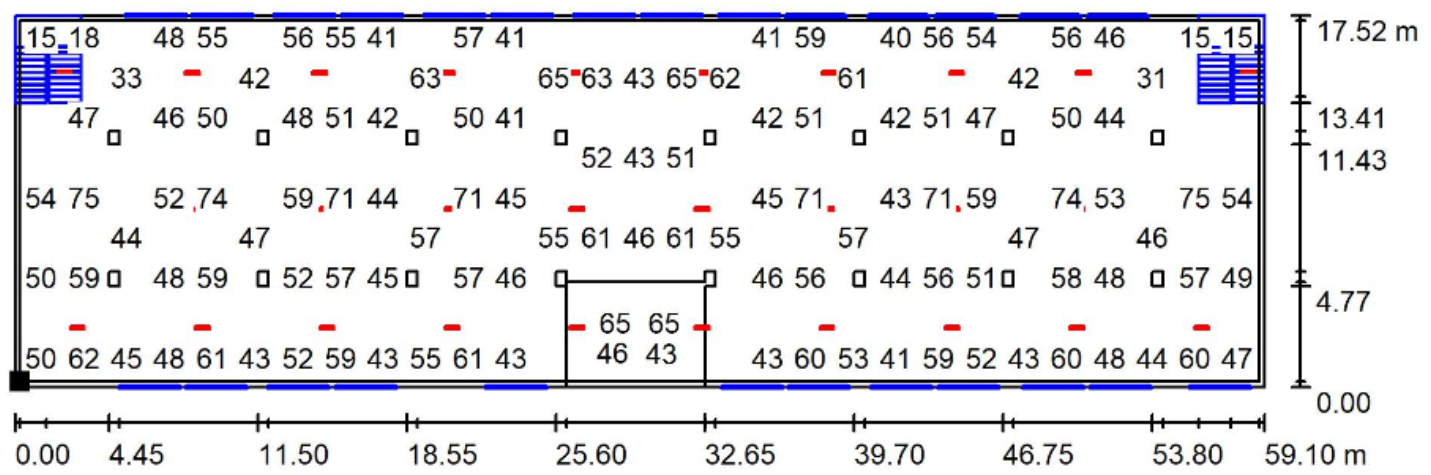

Fig. 3 Illuminance values (lx) simulated by Dialux 4.12 for the current lighting system.

maintenance factor of 0.8 , gave the graph of illuminance values shown in Fig. 3.

The graph in Fig. 3 shows illuminance values (expressed in lux) below the requirement established in international regulations for this type of facility (previously shown in Table 1). This supports the need to consider other lighting systems to guarantee the safety of the parking service users. Thus, as part of this research, eight other scenarios with different lighting systems were considered as alternatives for expert evaluation through the AHP multicriteria decision model with the goal to identify the most suitable one to the underground parking under study.

The decision criteria that were taken into account for the above mentioned purpose were: total power, average lifespan, life-cycle cost, maintained illuminance, uniformity, glare, energy efficiency, color rendering and energy saving.

The hierarchical decision model followed in this study for the selection of the most suitable lighting system using the AHP is shown in Table 2. There, the zero level represents the decision objective, level one the decision criteria considered and level two presents a selection of linear luminaires available in the Ecuadorian market.
TABLE II

HIERARCHICAL DECISION MODEL FOR LIGHTING SYSTEM SELECTION

\begin{tabular}{|c|c|c|c|}
\hline Level 0 & Objective & & $\begin{array}{l}\text { lect the best lighting system for the } \\
\text { ground parking under study }\end{array}$ \\
\hline \multirow{9}{*}{ Level 1} & \multirow{9}{*}{$\begin{array}{l}\text { Decision } \\
\text { criteria }\end{array}$} & $\mathrm{C} 1$ & Total power \\
\hline & & $\mathrm{C} 2$ & Lifespan \\
\hline & & $\mathrm{C} 3$ & Life-cycle cost \\
\hline & & $\mathrm{C} 4$ & Illuminance \\
\hline & & $\mathrm{C} 5$ & Uniformity \\
\hline & & C6 & Glare \\
\hline & & $\mathrm{C} 7$ & Energy efficiency \\
\hline & & $\mathrm{C} 8$ & Color rendering \\
\hline & & C9 & Energy saving \\
\hline \multirow{9}{*}{ Level 2} & \multirow{9}{*}{$\begin{array}{l}\text { Luminaire } \\
\text { alternatives }\end{array}$} & $\mathrm{A} 1$ & Feilosylvania 0056138 Sylproof Superia \\
\hline & & $\mathrm{A} 2$ & Feilosylvania 0051770 Syl-Louver V60 \\
\hline & & $\mathrm{A} 3$ & Feilosylvania 0059910 FTS \\
\hline & & $\mathrm{A} 4$ & Feilosylvania 0052060 Sylref-E \\
\hline & & A5 & Feilosylvania 0047883 Sylproof LED \\
\hline & & A6 & Feilosylvania 0047884 Sylproof LED \\
\hline & & A7 & Feilosylvania 0045120 Batten LED \\
\hline & & A8 & Philips BN124C \\
\hline & & A9 & Philips TMS022 \\
\hline
\end{tabular}

$17^{\text {th }}$ LACCEI International Multi-Conference for Engineering, Education, and Technology: "Industry, Innovation, And Infrastructure for Sustainable Cities and Communities", 24-26 July 2019, Jamaica. 
The comparison of the importance between each pair of criteria was made through the consensus of 12 experts in energy efficiency. Table 3 shows the modal values of the scale of importance assigned by the experts to each pair of criteria.

TABLE III

MODAL VALUES OF IMPORTANCE ASSIGNED BY THE EXPERTS TO DECISION CRITERIA

\begin{tabular}{|c|c|c|c|c|c|c|c|c|c|c|}
\hline \multirow{2}{*}{$\mathrm{C}_{\mathrm{i}}$} & \multicolumn{7}{|c|}{ Scale of comparison of the importance of criterion $\mathrm{i}\left(\mathrm{C}_{\mathrm{i}}\right)$} & \multirow{2}{*}{$\mathrm{C}_{\mathrm{j}}$} \\
\hline & 9 & 7 & 5 & 3 & 1 & $1 / 3$ & $1 / 5$ & $1 / 7$ & $1 / 9$ & \\
\hline $\mathrm{C} 1$ & & & & & $\mathrm{X}$ & & & & & $\mathrm{C} 2$ \\
\hline $\mathrm{C} 1$ & & & & & $\mathrm{X}$ & & & & & $\mathrm{C} 3$ \\
\hline $\mathrm{C} 1$ & & & & $\mathrm{X}$ & & & & & & $\mathrm{C} 4$ \\
\hline $\mathrm{C} 1$ & & & & & $\mathrm{X}$ & & & & & $\mathrm{C} 5$ \\
\hline $\mathrm{C} 1$ & & & $\mathrm{X}$ & & & & & & & $\mathrm{C} 6$ \\
\hline $\mathrm{C} 1$ & & & & & $\mathrm{X}$ & & & & & $\mathrm{C} 7$ \\
\hline $\mathrm{C} 1$ & & $\mathrm{X}$ & & & & & & & & $\mathrm{C} 8$ \\
\hline $\mathrm{C} 2$ & & & & & $\mathrm{X}$ & & & & & $\mathrm{C} 9$ \\
\hline $\mathrm{C} 2$ & & & & & & $\mathrm{X}$ & & & & $\mathrm{C} 3$ \\
\hline $\mathrm{C} 2$ & & & & & & $\mathrm{X}$ & & & & $\mathrm{C} 5$ \\
\hline $\mathrm{C} 2$ & & & $\mathrm{X}$ & & & & & & & $\mathrm{C} 6$ \\
\hline $\mathrm{C} 2$ & & & & & & $\mathrm{X}$ & & & & $\mathrm{C} 7$ \\
\hline $\mathrm{C} 2$ & & $\mathrm{X}$ & & & & & & & & $\mathrm{C} 8$ \\
\hline $\mathrm{C} 2$ & & & & $\mathrm{X}$ & & & & & & $\mathrm{C} 9$ \\
\hline $\mathrm{C} 3$ & & & & $\mathrm{X}$ & & & & & & $\mathrm{C} 4$ \\
\hline $\mathrm{C} 3$ & & & & & $\mathrm{X}$ & & & & & $\mathrm{C} 5$ \\
\hline $\mathrm{C} 3$ & & & & $\mathrm{X}$ & & & & & & $\mathrm{C} 6$ \\
\hline $\mathrm{C} 3$ & & & & & $\mathrm{X}$ & & & & & $\mathrm{C} 7$ \\
\hline $\mathrm{C} 3$ & $\mathrm{X}$ & & & & & & & & & $\mathrm{C} 8$ \\
\hline $\mathrm{C} 3$ & & & & & $\mathrm{X}$ & & & & & $\mathrm{C} 9$ \\
\hline $\mathrm{C} 4$ & & & & & $\mathrm{X}$ & & & & & $\mathrm{C} 5$ \\
\hline $\mathrm{C} 4$ & & & & $\mathrm{X}$ & & & & & & $\mathrm{C} 6$ \\
\hline $\mathrm{C} 4$ & & & & & $\mathrm{X}$ & & & & & $\mathrm{C} 7$ \\
\hline $\mathrm{C} 4$ & & $\mathrm{X}$ & & & & & & & & $\mathrm{C} 8$ \\
\hline $\mathrm{C} 4$ & & & & & & $\mathrm{X}$ & & & & $\mathrm{C} 9$ \\
\hline $\mathrm{C} 5$ & & & $\mathrm{X}$ & & & & & & & $\mathrm{C} 6$ \\
\hline $\mathrm{C} 5$ & & & & & $\mathrm{X}$ & & & & & $\mathrm{C} 7$ \\
\hline $\mathrm{C} 5$ & & & $\mathrm{X}$ & & & & & & & $\mathrm{C} 8$ \\
\hline $\mathrm{C} 5$ & & & & $\mathrm{X}$ & & & & & & $\mathrm{C} 9$ \\
\hline $\mathrm{C} 6$ & & & & & & & $\mathrm{X}$ & & & $\mathrm{C} 7$ \\
\hline $\mathrm{C} 6$ & & & & $\mathrm{X}$ & & & & & & $\mathrm{C} 8$ \\
\hline $\mathrm{C} 6$ & & & & & & & $\mathrm{X}$ & & & $\mathrm{C} 9$ \\
\hline $\mathrm{C} 7$ & & $\mathrm{X}$ & & & & & & & & $\mathrm{C} 8$ \\
\hline $\mathrm{C} 7$ & & & & & $\mathrm{X}$ & & & & & $\mathrm{C} 9$ \\
\hline
\end{tabular}

The reliability of the answers assigned by the experts in the survey was obtained through the Friedman's test and the Kendall's concordance test. The significance of the Friedman's test turned out to be less than 0.05 , which ensures with $95 \%$ confidence that the nine decision criteria do not have the same importance, which is a necessary and sufficient condition to demonstrate the validity of the results. The coefficient of Kendall, on the other hand, obtained a value of 0.816 , in being greater than 0.5 it can be affirmed that there is a non-casual agreement among the experts, which ensures the reliability of the results of the survey.

The comparison of the importance or preference between each pair of criteria by means of the Saaty's scale [9], led to a reciprocal matrix (R), so that $\mathrm{r}_{\mathrm{ij}}$ represents the relative priority between criterion $C_{i}$ and criterion $C_{j}$ with respect to the objective or goal of the problem.

$$
R=\left|\begin{array}{ccccccccc}
1 & 1 & 1 & 3 & 1 & 5 & 1 & 7 & 1 \\
1 & 1 & 1 / 3 & 1 / 3 & 1 / 3 & 5 & 1 / 3 & 7 & 3 \\
1 & 3 & 1 & 3 & 1 & 3 & 1 & 9 & 1 \\
3 & 3 & 1 / 3 & 1 & 1 & 3 & 1 & 7 & 1 / 3 \\
1 & 3 & 1 & 1 & 1 & 5 & 1 & 5 & 3 \\
1 / 5 & 1 / 5 & 1 / 3 & 1 / 3 & 1 / 5 & 1 & 1 / 5 & 3 & 1 / 5 \\
1 & 3 & 1 & 1 & 1 & 5 & 1 & 7 & 1 \\
1 / 7 & 1 / 7 & 1 / 9 & 1 / 7 & 1 / 5 & 1 / 3 & 1 / 7 & 1 & 1 / 9 \\
1 & 1 / 3 & 1 & 3 & 1 / 3 & 5 & 1 & 9 & 1
\end{array}\right|
$$

The results of the normalization of the paired comparisons are presented in the Rnorm Matrix and the resulting priority vector is shown in the $\mathrm{W}$ matrix.

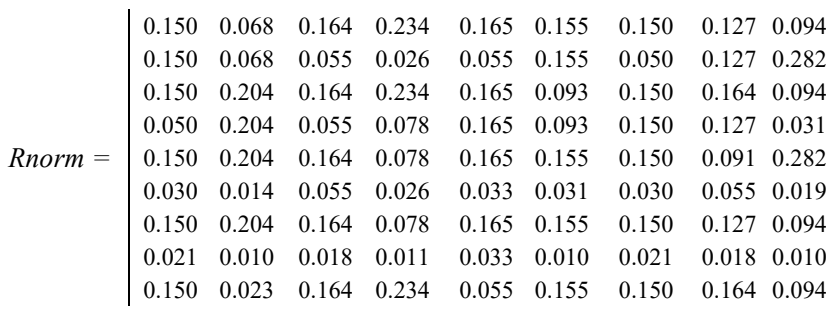

$$
W=\left|\begin{array}{l}
0.1451 \\
0.1075 \\
0.1574 \\
0.1059 \\
0.1598 \\
0.0324 \\
0.1429 \\
0.0171 \\
0.1319
\end{array}\right|
$$

The process of paired comparisons of the criteria yielded a consistency index of $9.08 \%$, which means that the $\mathrm{R}$ matrix has an admissible consistency and the vector of priorities obtained (W matrix) is accepted as valid.

As it could be interpreted from Table 2, all decision criteria are quantitative variables, so it would not be relevant to make comparisons between alternatives with respect to each variable by means of Saaty's subjective scale. Consequently, with the values identified for each decision variable in each alternative the $M$ matrix was generated, where each $\mathrm{m}_{\mathrm{ij}}$ represents the value that the lighting system alternative $\mathrm{i}$ obtained in variable $\mathrm{j}$.

$M=\left|\begin{array}{ccccccccc}1824 & 10000 & 3508.96 & 79 & 0.696 & 18 & 1.76 & 84 & 0 \\ 3010 & 20000 & 7079.33 & 123 & 0.524 & 17 & 2.91 & 84 & 0 \\ 1716 & 25000 & 5017.03 & 119 & 0.566 & 20 & 1.66 & 85 & 6 \\ 2150 & 25000 & 6311.67 & 129 & 0.625 & 21 & 2.08 & 84 & 0 \\ 1408 & 50000 & 8014.51 & 127 & 0.611 & 26 & 1.36 & 80 & 23 \\ 1194 & 50000 & 6840.63 & 110 & 0.62 & 26 & 1.15 & 85 & 35 \\ 1200 & 30000 & 5075.17 & 79 & 0.671 & 23 & 1.16 & 85 & 34 \\ 1560 & 50000 & 7890.57 & 140 & 0.587 & 24 & 1.51 & 85 & 14 \\ 2160 & 50000 & 10498.30 & 138 & 0.617 & 23 & 2.09 & 85 & 0\end{array}\right|$

$17^{\text {th }}$ LACCEI International Multi-Conference for Engineering, Education, and Technology: "Industry, Innovation, And Infrastructure for Sustainable Cities and Communities", 24-26 July 2019, Jamaica. 
It should be noted that optimal power, life-cycle cost and glare criteria are to be minimized, while the rest are to be maximized. In this way, it was necessary to homogenize the $M$ matrix to the Mnorm matrix. The latter is composed of all the local priority vectors of the alternatives for each criterion.

Mnorm $=\left|\begin{array}{lllllllll}0.394 & 0.200 & 0.6658 & 0.564 & 1.000 & 0.308 & 0.605 & 0.988 & 0.000 \\ 0.000 & 0.400 & 0.3257 & 0.879 & 0.753 & 0.346 & 1.000 & 0.988 & 0.000 \\ 0.430 & 0.500 & 0.5221 & 0.850 & 0.813 & 0.231 & 0.570 & 1.000 & 0.171 \\ 0.286 & 0.500 & 0.3988 & 0.921 & 0.898 & 0.192 & 0.715 & 0.988 & 0.000 \\ 0.532 & 1.000 & 0.2366 & 0.907 & 0.878 & 0.000 & 0.467 & 0.941 & 0.660 \\ 0.603 & 1.000 & 0.3484 & 0.786 & 0.891 & 0.000 & 0.395 & 1.000 & 1.000 \\ 0.601 & 0.600 & 0.5166 & 0.564 & 0.964 & 0.115 & 0.399 & 1.000 & 0.990 \\ 0.482 & 1.000 & 0.2484 & 1.000 & 0.843 & 0.077 & 0.519 & 1.000 & 0.419 \\ 0.282 & 1.000 & 0.0000 & 0.986 & 0.886 & 0.115 & 0.718 & 1.000 & 0.000\end{array}\right|$

Then, the global priority vector of the alternatives was obtained from the product of the priority vectors of each alternative with respect to the decision criteria (Mnorm Matrix) and the priority vector of the criteria with respect to the objective (W Matrix).

Mnorm $\cdot W=\mid \begin{aligned} & 0.5163 \\ & 0.4786 \\ & 0.5470 \\ & 0.5243 \\ & 0.6282 \\ & 0.6809 \\ & 0.6553 \\ & 0.6061 \\ & 0.5179\end{aligned}$

From this it is concluded that the most suitable lighting system alternative according to the previously defined decision criteria is the sixth (see Table I). Such system comprise luminaires that contains a linear LED lamp of $1565 \mathrm{~mm}$ length, emits neutral white light (color temperature equal to $4000 \mathrm{~K}$ ), has a power of $37 \mathrm{~W}$, lifespan of 50000 hours, wholesale price of $\$ 45.28$, IRC $=85$, luminous flux of $3794 \mathrm{~lm}$ and an average efficiency of $101 \mathrm{~lm} / \mathrm{W}$. The luminaire includes a body and a diffuser of high resistance polycarbonate that offers IP65 protection against moisture and dust, and an IK08 classification against impacts. In addition, it provides optimal distribution of light with reduced glare and its fixing brackets and locking clips are made of stainless steel, guaranteeing a long durability.

This system would consist of 32 LED luminaires and its implementation would allow an annual expected energy saving of $35 \%$ compared to the current installed system.

\section{DISCUSSION}

This research shows that the use of Analytical Hierarchical Process (AHP) may be relevant in the selection of suitable lighting systems for indoor facilities such as underground parkings, which have been little discussed in the literature.
Using DIALux 4.12 software, the facility under study was modelled and nine scenarios with different types of luminaires were simulated. In all of them, technical criteria such as power consumption, illuminance at ground level, uniformity, glare and energy efficiency were analysed. In addition, the behaviour of other variables that depend on the type of luminaire selected such as the lifespan and color rendering were also considered. Likewise, the lighting system life-cycle cost was measured for every scenario, as well as the energy saving that the system on trial would represent with respect to the system currently implemented.

DIALux is one of the most commonly used tools in the simulation of lighting systems [1], [4], [6], [8], [11]-[15]. In this sense, this research demonstrates that the results of the simulation in DIALux are very similar to those of field measurements, confirming what was reported in previous studies [11], [15].

As a result of the application of the AHP, it was determined that the most suitable luminaire alternative according to the previously defined decision criteria for the underground parking under study is the Feilosylvania 0047884 Sylproof, which uses LED technology (Light-Emitting Diodes). Apparently this result is not coincidental, because in recent years several studies have considered the implementation of LED lighting as a strategy to reduce the electric power consumption in indoor and outdoor facilities given its high efficiency, duration and low maintenance cost [1], [4], [6], [8], [11], [15]. However, these studies start from the use of a specific luminaire model, devaluing the analysis of other alternatives through a multicriteria decision method. In this research, the application of AHP for this purpose demonstrated feasibility and pertinence.

Certainly the use of AHP in the selection of interior lighting systems is not a novel issue [16]-[18]. However, the relevance of this study relies in the combination of economic criteria (such as life-cycle cost) and energy saving along with luminaires characteristics (such as lifespan and color rendering) and other lighting parameters previously simulated (e. g. illuminance, power consumption, uniformity, glare, and energy efficiency). The above shows the rigor and objectivity of the decision process here performed to select the appropriate lighting system for the indoor facility under study. Hence, the selection criteria proposed in this research, as well as their respective levels of relative importance can constitute a starting point to strengthen related decision-making processes in future research.

In particular, the priority vector of the decision criteria identified in this study showed that lighting uniformity was the most influential criterion in the decision process according to experts' judgement. Consequently, in decreasing order of influence the following criteria were identified: life-cycle cost, power consumption, energy efficiency, energy saving, lifespan, illuminance, glare and color rendering. The previous outcome relates with the one revealed in [16], where economic criteria

$17^{\text {th }}$ LACCEI International Multi-Conference for Engineering, Education, and Technology: "Industry, Innovation, And Infrastructure for Sustainable Cities and Communities", 24-26 July 2019, Jamaica. 
such as lighting system life-cycle cost had a higher level of influence on the final decision over technical parameters such as illuminance.

\section{CONCLUSIONS}

A light audit performed at the underground parking of an academic building in Ecuador showed incompliance with international illumination standards in its parking areas, interior circulation lanes and access/exit ramps. Thus, this study presented an AHP-based decision process selection that allowed to find a suitable lighting system based on relevant technical and economic criteria so as to guarantee the safety of the users and the operations that take place in that space of common use.

The LED technology-based lighting system suggested as a result of the AHP method application in this research complies with the EN 12464.1 illumination standards for underground parkings, and at the same time, its implementation would represent an annual energy saving of $35 \%$ compared to the current fluorescent lighting system under operation.

The results of this work could constitute a good reference for future studies to combine simulated parameters with other technical and economic decision criteria in the decision process for indoor facilities lighting system selection.

The energy saving resulted from the implementation of more efficient lighting systems would positively impact the reduction of greenhouse gases emission into the atmosphere. In this sense, future research should also pay more attention to the combination of more efficient lighting systems with cleaner energy sources, to maximize the contribution that is made from the academy to the sustainability of the environment.

\section{REFERENCES}

[1] P. Sathya and R. Natarajan, "Energy estimation and photometric measurements of LED lighting in laboratory," in 2014 International Conference on Advances in Electrical Engineering (ICAEE), 2014, pp. $1-5$.

[2] M. M. Aman, G. B. Jasmon, H. Mokhlis, and A. H. A. Bakar, "Analysis of the performance of domestic lighting lamps," Energy Policy, vol. 52, pp. 482-500, Jan. 2013.

[3] B. Gayral, "LEDs for lighting: Basic physics and prospects for energy savings," Comptes Rendus Phys., vol. 18, no. 7-8, pp. 453-461, Sep. 2017.

[4] F. Salata, I. Golasi, M. di Salvatore, and A. de Lieto Vollaro, "Energy and reliability optimization of a system that combines daylighting and artificial sources. A case study carried out in academic buildings," Appl. Energy, vol. 169, pp. 250-266, May 2016.

[5] B. Atanasiu, C. Despret, M. Economidou, J. Maio, I. Nolte, and O. Rapf, "Europe's Buildings under the Microscope: A Country-byCountry Review of the Energy Performance of Buildings," Build. Perform. Inst. Eur., 2011.

[6] N. Tshikuvhe, M. Nthontho, S. P. Chowdhury, and S. Chowdhury, "Cost effective carbon mitigation through energy efficiency: A case for a university student residence lighting in Cape Town," in 2013 Africon, 2013, pp. 1-5.

[7] European Committee for Standardization, Iluminación de los lugares de trabajo en interiores. Unión Europea, 2002, p. 15.

[8] S. Ji, G. Cao, J. Zhang, F. Yu, D. Li, and J. Yu, "Lighting design of underground parking with tubular daylighting devices and LEDs," Opt. - Int. J. Light Electron Opt., vol. 127, no. 3, pp. 1213-1216, Feb. 2016.

[9] Instituto Ecuatoriano de Seguridad Social, Reglamento de Seguridad y salud de los trabajadores y mejoramiento del ambiente de trabajo. Ecuador, 1986, p. 92.

[10] T. L. Saaty, "Decision making with the analytic hierarchy process," Int. J. Serv. Sci., vol. 1, no. 1, pp. 83-98, 2008.

[11] P. K. Soori and S. Alzubaidi, "Study on improving the energy efficiency of office building's lighting system design," in 2011 IEEE GCC Conference and Exhibition, GCC 2011, 2011, pp. 585-588.

[12] L. Alboteanu and G. Manolea, "Photovoltaic lighting for an educational room," in 2013 4th International Symposium on Electrical and Electronics Engineering (ISEEE), 2013, pp. 1-6.

[13] S. Alzubaidi and P. K. Soori, "Energy Efficient Lighting System Design for Hospitals Diagnostic and Treatment Room-A Case Study," J. Light Vis. Environ., vol. 36, no. 1, pp. 23-31, 2012.

[14] L. E. Mavromatidis, X. Marsault, and H. Lequay, "Daylight factor estimation at an early design stage to reduce buildings' energy consumption due to artificial lighting: A numerical approach based on Doehlert and Box-Behnken designs," Energy, vol. 65, pp. 488-502, 2014.

[15] K. Zalatis and K. Berzina, "Effective and optimal simulation of light design in Riga Technical university's lighting laboratory from the point of view of energy efficiency," in 2016 IEEE 4th Workshop on Advances in Information, Electronic and Electrical Engineering (AIEEE), 2016, pp. 1-9.

[16] O. Alshamrani, A. Alshibani, and M. Alogaili, "Analytic Hierarchy Process \& Multi Attribute Utility Theory Based Approach for the Selection of Lighting Systems in Residential Buildings: A Case Study," Buildings, vol. 8, no. 6, p. 73, May 2018.

[17] F. Lv, Z. Wang, Y. Ding, Y. Li, and N. Zhu, "A systematic method for evaluating the effects of efficient lighting project in China," Energy Effic., vol. 9, no. 5, pp. 1037-1052, Oct. 2016.

[18] T. M. Chung and R. T. H. Ng, "The application of analytic hierarchy process in daylighting performance assessment," Indoor Built Environ., vol. 25, no. 1, pp. 50-68, 2016.

$17^{\text {th }}$ LACCEI International Multi-Conference for Engineering, Education, and Technology: "Industry, Innovation, And Infrastructure for Sustainable Cities and Communities”, 24-26 July 2019, Jamaica. 